\title{
Social Media and Research Visibility
}

\author{
R.T. Fitzgerald and A. Radmanesh
}

A ssessing the value of scientific research output, an important component of academic promotion and tenure, is increasingly based on metrics such as the Impact Factor, $\mathrm{H}$-index, and more recently Google Scholar, that attempt to numerically encapsulate an author's productivity and scholarly impact. The H-index, discussed by AJNR Editor-in-Chief Mauricio Castillo in a 2010 editorial, ${ }^{1}$ and an expanding alphabet soup of additional measurement tools (M-index, C-index, S-index, E-index, etc) are based on article citations accumulated over time. As such, it behooves researchers to consider avenues to expand the reach and visibility of their work. It is expected that article influence will soon be used by funding entities to assign monies for research. Social media represent a potential opportunity to do so, and may be particularly important in an era in which the link between an article's citation rate and its publishing journal is in decline. ${ }^{2}$

A growing body of literature has examined the impact of social media on views and citations of scholarly articles. Tweets containing a link to an article, or "tweetations" have been shown to predict highly cited articles within the first 3 days after publication. ${ }^{3}$ Randomly selected articles that are disseminated via social media (Twitter, Facebook, LinkedIn) are viewed and downloaded more frequently than unselected papers. ${ }^{4}$ Thewall et $\mathrm{al}^{5}$ showed a positive correlation between altmetrics (a measure of citations or mentions in specific social media services) and eventual citations, with the strongest evidence for articles posted on Twitter, Facebook wall posts, and blog entries. Other authors found a less robust correlation between tweets and citations and have suggested that these metrics may represent different yet complementary measures of an article's value. ${ }^{6}$ Further studies are required to fully assess the long-term relationship between altmetrics and traditional measures of scholarly value.

From the Department of Radiology (R.T.F.), University of Arkansas for Medical Sciences, Little Rock, Arkansas; and Mallinckrodt Institute of Radiology (A.R.), Washington University School of Medicine, St Louis, Missouri.

Please address correspondence to Ryan T. Fitzgerald, MD, Department of Radiology, University of Arkansas for Medical Sciences, 4301 W Markham St, Little Rock, AR 72205; e-mail: fitzgeraldryant@uams.edu; @ryantfitzgerald

http://dx.doi.org/10.3174/ajnr.A4054
Despite evidence supporting the potential benefits of social media engagement for researchers, adoption of social media in academia has been slow. It is estimated that fewer than $3 \%$ of scientists are active Twitter users. ${ }^{7}$ A study to assess the prevalence of social media mentions in 1.4 million scholarly articles published between 2010 and 2012, fewer than 10\% were tweeted at least once; however, the rate of tweets increased substantially over the 3-year study period from $2.4 \%$ in 2010 to $20.4 \%$ in $2012 .{ }^{6}$ General science and medicine journals such as Nature (@nature) and the New England Journal of Medicine (@nejm) enjoy a greater abundance of followers relative to subspecialty journals such as $A J N R$, and thus their articles are more likely to be frequently retweeted. Most journals (67\%) have less than 20\% of their content tweeted. ${ }^{6}$ AJNR (@AmJNeuroradiol) tweets each and every article that appears in our pages. We invite AJNR authors to include their Twitter handles in the author contact information list of new submissions to facilitate professional networking and potential collaborations.

\section{REFERENCES}

1. Castillo M. Measuring academic output: the H-index. AJNR Am J Neuroradiol 2010;31:783-84

2. Lozano GA, Larivière V, Gingras Y. The weakening relationship between the impact factor and papers' citations in the digital age. J Am Soc Inf Sci 2012;63:2140-45

3. Eysenbach G. Can tweets predict citations? Metrics of social impact based on Twitter and correlation with traditional metrics of scientific impact. J Med Internet Res 2011;13:e123

4. Allen HG, Stanton TR, Di Pietro F, et al. Social media release increases dissemination of original articles in the clinical pain sciences. PLoS One 2013;8:e68914

5. Thelwall M, Haustein S, Larivière V, et al. Do altmetrics work? Twitter and ten other social web services. PLoS One 2013;8:e64841

6. Haustein S, Peters I, Sugimoto CR, et al. Tweeting biomedicine: an analysis of tweets and citations in the biomedical literature. $J \mathrm{Am}$ Soc Inf Sci 2014;65:656-69

7. Priem J, Costello KL, Dzuba T. Prevalence and use of Twitter among scholars. figshare. Published December 16, 2012. doi: 10.6084/ m9.figshare. 104629 